\title{
Performance management of investment projects based on real option theory and method of analysis of hierarchies
}

\author{
L.A. Baev $^{1, *}$, and O.V. Egorova ${ }^{1}$ \\ ${ }^{1}$ South Ural state University, Chelyabinsk, Russia
}

\begin{abstract}
The article is devoted to the development of the method for evaluation and control of investment projects efficiency in conditions of high uncertainty. There are marked the limitations of the traditional evaluation methods of investment projects efficiency and proposed more relevant approach based on the application of real option theory, which allows evaluating projects with consideration of their multivariate and opportunity of decision making at every stage of their development. The article shows that, despite the high relevance of real option theory, its practical use is very difficult for a number of reasons. The main problem in estimating the value of real options is the need to use a sufficient number of a priori statistics regarding the project, which in practice is difficult. The authors propose a method in which the probabilistic characteristics of the model project are replaced with the correct expert ratings, named the modified ROV method (MROV). The method is based on the binomial model of real option value assessing, based on the building of a decision tree, at each node of which there is possible the development according to the "optimistic" or "pessimistic" forecast. Since the development of the project under any scenario depends on a number of criteria environments, the task of assessing the value of real options becomes a multicriteria task. One of the most reasonable and practically relevant methods of solving such problems is the method of analytic hierarchy process (AHP), which is used in the basis of the developed MROV-method. The article also details the algorithm of the method application to determine quantitative estimates of the relative probabilities of the development of the project on "optimistic" or "pessimistic" scenario in each node of the binomial tree. Obtained estimates are used as weights in the calculation of the net present value of the optional investment project for a decision on the feasibility of its realization and inclusion in the project evaluated real options.
\end{abstract}

\section{Introduction}

Analysis and assessment of investment projects efficiency is one of the most difficult tasks of economic management. The complexity of this task is caused by the high degree of uncertainty of conditions of the projects realization. On the one hand, it is necessary to foresee the future, and on the other hand all indicators of efficiency of projects calculated on the basis of strict script implementation and does not take into account possible changes.

\section{The actuality of the research}

Topicality of the research is defined by need of development of methods of assessment and management of investment project efficiency as multi-stage processes with a high level of diversity and uncertainty.

In recent years, the approach to the evaluation of investment projects based on application of the theory of real options becomes commonly used. It allows evaluating the project taking into account the various options step-by-step development.
The evaluation methodology of real options is in the stage of rapid growth $[1-8,11]$. An increasing number of companies use it for the formation of its development strategy. The idea of the approach is that the uncertainty of the project realization conditions contains not only risks but also opportunities that must be considered at the planning stage of projects, putting in the project the necessary conditions of their realization, that is real option $[9,10]$. Thus, for the decision it is required the valuation of the option [12-15].

Despite the high relevance of the theory of real options and the potential for development on its basis a new direction of a priori adaptive performance management of investment projects, the practical use of the ideas of this theory very difficult for a number of reasons.

\section{Existing approaches and solutions}

Existing approaches to assessing the value of real options come from the unity of the theoretical and methodological basis of real and financial options $[3,7,16,17]$. 
Financial option - an option to purchase or to sell a financial asset in the event of a predicted changes in its future value.

Real option - the possibility of correction of the cash flows of the project, in case of predicted changes of its realization.

This allows us to conclude that since theoretically financial and real options are similar, technologically, the existing traditional different approaches to the valuation of financial options can be used for the evaluation of the real options $[3,12,16]$. It is important to understand that even theoretically this approach is possible only for "simple" options, which have only one source of uncertainty and which are based on an underlying asset. In this case, due to the variety of real options, it is required the development of a greater number of special methods and techniques. Discussing this area of research, we need to understand that the development of a methodology of evaluation of financial options, applied to real options does not remove the need for correct quantitative estimation of the probabilistic characteristics of the different trajectories of development of the project, which, as previously noted, is not practicable. Not rejecting the idea of using financial options theory to valuation of real options, let's focus on construction methods, eliminating this restriction.

Fig.1 shows the developed algorithm of selection of the most appropriate methods of financial options assessment, applied to the problem of real options evaluation, taking into account existing constraints and problems associated with their application.

In Fig. 1 there are the following symbols:

$C_{e s p}^{\text {call }}$ - the price of the European call option; $S$ - the price of the underlying asset at the time of purchase of the option; $X$ - the strike price (the price of the underlying asset); $r$ - the continuously compounded risk free rate; $e$ - base of the natural logarithm; $T$ - the expiry time; $N(d 1)$ - function of the normal distribution, which can be regarded as the risk-neutral probability that the option will gain; $N(d 2)$ - function of the normal distribution, which is seen as the probability that the option will be exercised.

Fig. 1 shows that the known transformation methods of assessment do not remove the underlying problem of the need to use a sufficient number of a priori statistics on the project.

In addition, the analysis shows that the BlackScholes Option Pricing Model and its modifications will be correct for a very narrow class of the optional projects even in the purely theoretical case of known stochastic characteristics of the project variables.

The binomial model provides a much higher flexibility [18-20].

In accordance with the binomial model the entire period of the option is broken into a number of intervals, during each of which the value of the underlying asset may increase with the probability $q$ or decrease with the probability $(1-q)$. The most known method of real options valuation (ROV - real option valuation method) is based on this approach, which, however, requires a stochastic characteristic of decision tree - function of density of distribution of probability of growth or decline of the asset value in the tree nodes.

$$
\begin{aligned}
& \text { The original (base) Black - Scholes Option Pricing Model } \\
& \qquad C_{e B p}^{\text {call }}=S \times N\left(d_{1}\right)-X e^{-r T} \times N\left(d_{2}\right)
\end{aligned}
$$

\begin{tabular}{|c|c|}
\hline \multicolumn{2}{|c|}{$\begin{array}{l}\text { Application area: "call" option of the American type } \\
\text { without dividend to be paid }\end{array}$} \\
\hline $\begin{array}{l}\text { Specifics of real options: } \\
\text { 1. The underlying asset is not } \\
\text { traded; } \\
\text { 2. The price of the asset does } \\
\text { not change continuously; } \\
\text { 3. Variance is unknown and } \\
\text { unstable; } \\
\text { 4. Instant execution of the } \\
\text { option. }\end{array}$ & $\begin{array}{l}\text { Objectives: } \\
\text { 1. To determine the risk- } \\
\text { free rate; } \\
2 \text {. To estimate the } \\
\text { variance; } \\
\text { 3. To determine the } \\
\text { expiry time of the option. }\end{array}$ \\
\hline solution & of the application area \\
\hline \multicolumn{2}{|c|}{$\begin{array}{l}\text { Modified by R. Merton model } \\
C_{e s p}^{\text {call }}=S e^{-d T} \times N\left(d_{1}\right)-X e^{-r T} \times N\left(d_{2}\right)\end{array}$} \\
\hline \multicolumn{2}{|c|}{$\begin{array}{l}\text { Application: "call" options of American type with dividends to } \\
\text { be paid }\end{array}$} \\
\hline $\begin{array}{l}\text { Limitations: the possibility } \\
\text { of accounting for early } \\
\text { exercise of the option }\end{array}$ & $\begin{array}{l}\text { Objectives: to assess the } \\
\text { real loss of income as } \\
\text { analogous to the dividend }\end{array}$ \\
\hline \multicolumn{2}{|l|}{$\begin{array}{l}\text { the solution to the } \\
\text { nroblem }\end{array}$} \\
\hline \multicolumn{2}{|c|}{ A modified version of the binomial model } \\
\hline fatal flaw & $>$ \\
\hline $\begin{array}{l}\text { The necessity of determining } \\
\text { characteristics of the project }\end{array}$ & $\begin{array}{l}\text { e probabilistic } \\
\text { ables }\end{array}$ \\
\hline
\end{tabular}

Fig.1. Algorithm of the real options evaluation methods selection.

According to the authors, this fundamental limitation can be eliminated as follows.

1. It must be emphasized as a well-known postulate that the purpose of the analysis and synthesis of investment projects is not a precise calculation of the optimum parameters and maximization of the known criteria of effectiveness, but the choice of the most rational conditions and trajectory of the project.

2. The correct method of expert estimation of the relative probability of positive or negative outcome of the previous 
administrative decision in the node of the decision tree must be used.

However, the issue of real option valuation is not only about of how much money we earn, it is also about of the use of the method from positions of real opportunities to receive additional positive net cash flows in principle. To answer on this question it is enough to consider two alternatives: optimistic and pessimistic.

Thus, the managerial task of the real options valuation comes down to the valuation of the relative probability of the outcomes of a binomial option. Therefore, a binomial model of valuation of the real option is taken as the bases of the proposed for development MROV-method (MROVmodified real option valuation method).

The proposed method is essentially a modification of the known ROV method, with correct replacement of "accurate" assessment of probability of branches on the decision tree for the expert assessment of the comparative probabilities of optimistic and pessimistic outcomes of previous management decisions.

The meaning is that according to the binomial model, at each stage of the project (at each node a binomial decision tree) there are two possible ways of its development (Fig.2). 1. Optimistic variant: value of the criterion is higher (better) than baseline value $X_{1}>X_{o}$ with a probability $p_{1}$;

2. Pessimistic variant: value of the criterion is lower (worse) than baseline value $X_{2}<X_{o}$ with probability $p_{2}$.

\begin{tabular}{c|c}
\multicolumn{1}{c}{$\begin{array}{l}\text { Optimistic variant, } \\
\text { probability } p_{1}\end{array}$} \\
\cline { 2 - 2 } $\begin{array}{c}\text { The base value of the } \\
\text { criterion }\end{array}$ \\
\hline$X_{0}>X_{O}$ \\
\hline \\
\\
\end{tabular}

Fig. 2. The ratio of probabilities of alternatives.

It is important to note, that while judging, the sum of the probabilities $p_{1}$ and $p_{2}$ may not be equal to 1 , since other options are possible when the value can be in the range between $X_{1}$ and $X_{2}$.

It should be noted that the proposed approach is more correct than the classical ROV-method. The fact that the binomial model of the real options valuation is based on constructing of a decision tree, in each node of which there are two types of events: the development of the project in an optimistic or pessimistic forecast. Moreover, the degree of optimism and pessimism is determined by the project managers of the enterprise that realize the project. The absolute probability of each of the specific forecasts will be equal to zero, therefore, the assessment of probabilities can be correct only in the sense of the answer to the question, how much more likely an optimistic situation, relatively pessimistic, or Vice versa. So the unranked absolute probability of the ROV-method is replaced by the estimated comparative probability of the MROV-method.
The development of the project on a particular forecast depends on a number of criteria of the environment in which the project is located. Thus, the problem of estimating of the real options value becomes a multi-criteria problem which can be solved by using one of the methods of expert estimation, specially designed for such tasks. The essence of these methods is to build a hierarchical structure that allows to disaggregate the overall task into particular tasks.

One of the most reasonable and practically relevant methods of solving such problems is the Analytic Hierarchy Process (AHP). This method offers to split the global problem into a number of subtasks, allowing the same type of alternatives and the further processing of decision makers judgments from paired comparisons. Thus obtained judgments become the ratings in the scale of relations and correspond to the so-called hard, quantitative estimates $[21,22]$.

The advantages of the method (AHP) allow to select it as the technological basis for MROV-method, which can be carried out correctly, transparently and comprehended.

Algorithm of MROV-method implementation mean the use of AHR to determine the ratio of the relative probabilities of the project realization within optimistic and pessimistic economic forecast in binomial model of the optional investment project. Meanwhile the option realization is considered to be the optimistic scenario, and the missing of the option realization is considered to be a pessimistic scenario.

Omitting the details of the method applying within the proposed approach, we note that after the processing of the data, obtained from experts, by the procedure of synthesis of multiple judgments, quantitative estimates are determined. These estimates refer to the priorities of the analyzed criteria influence on the outcome of the project realization at any stage, and also the priorities of each of the alternatives relative to the criteria.

Evaluation is conducted at each node of the binomial decision tree, in thus case the hierarchical structure of the criteria may be individual for each node and can have any number of levels and criteria.

On the basis of the obtained results ranking values of the probabilities of the project development under any scenario in each node of the binomial tree are determined. The quantifying model of the relative values of the probabilities of the project development within optimistic or pessimistic scenario is a linear additive model, which is represented by formula (1):

$$
p_{i}=a_{1} \cdot x_{i 1}+a_{2} \cdot x_{i 2}+a_{3} \cdot x_{i 3}+a_{4} \cdot x_{i 4}+\ldots,
$$

where $p$ - ranking value of the probability of the project development on the $i$-th scenario (optimistic or pessimistic); $a_{1}, a_{2}, a_{3}, a_{4}$ - values of the priorities of criteria influence on the outcome of the project realization on the evaluated phase;

$x_{\mathrm{i} 1}, x_{\mathrm{i} 2}, x_{\mathrm{i} 3}, x_{\mathrm{i} 4}$ - values of the priorities of the $i$-th alternative relative to the relevant criteria.

As a result of the using of AHP, based on the formula (1), we obtain a ranking value of the relative probabilities of project realization according to the optimistic scenario $\left(p_{1}\right)$ and pessimistic scenario $\left(p_{2}\right)$. 
At the final stage the decision about the feasibility of the option investment project realization is made. This decision is based on the net present value calculation, which can be obtained by sequential discounting of the weighted values of the project cash flow. The ranked values of the probabilities obtained within AHR are used as the weights there.

Schematic representation of the described algorithm of the MROV-method implementation is presented in Fig.3.

\section{Conclusion (findings)}

The proposed approach can correctly implement methodological ideas of the optional approach to the development and analysis of investment projects, taking into account not only the uncertainty associated with risks, but also embedded in the project the options of its realization due to the uncertainty of the positive opportunities of the project development.

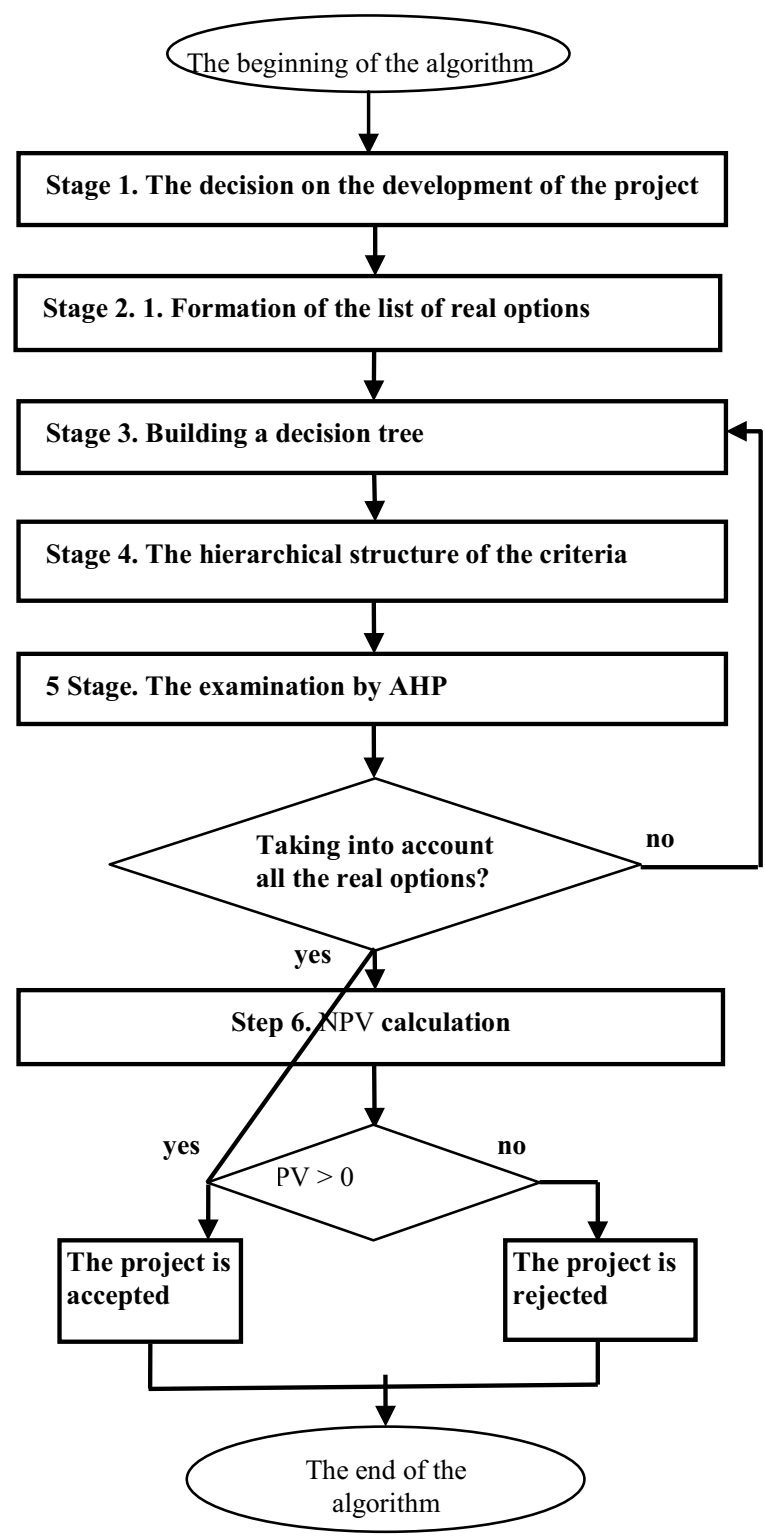

Fig. 3. Algorithm of the project valuation by MROV-method.

\section{References}

1. S. Vine, Options: Full course for professionals (Alpina Pablisher, Moscow, 2015)

2. V.A. Galanov, Derivatives (Infra-M, Moscow, 2014)

3. A. Damodaran, Investment valuation: Tools and techniques for the evaluation of any assets (Alpina Pablisher, Moscow, 2015)

4. M.A. Limitovskiy, Investment projects and real options in developing markets (Yurayt, Moscow, 2010)

5. I.V. Lipsits, V.V. Kossov, Economic analysis of real investments (Magistr, Moscow, 2010)

6. N. Bruslanova, Financial director, 7-8, 13-20 (2004)

7. A.V. Bukhvalov, Russian management journal, 1, 3 32 (2004)

8. T. Kouplend, T. Ostrovski, Vestnik McKinsey, 2, 113-132 (2002)

9. P. Boyle, Journal of Financial and Quantitative Analysis, 23(1), 1-12 (1988)

10. T. Copeland, Ph. Keenan, The McKinsey Quarterly, 3, 128-141 (1998)

11. A. Borison, Proc. 7th Annual International Conference on Real Options (2003)

12. R. Geske, Journal of Financial Economics, 7, 375380 (1979)

13. B. Kamrad, P. Ritchken, Management Science, 37(12), 1640-1652 (1991)

14. R.M. Stulz, Journal of Financial Economics, 10(2), 161-185 (1982)

15. L. Trigeorgis, Real Options - Managerial Flexibility and Strategy in Resource Allocation: The MIT Press (1996)

16. R. Breyli, S. Mayers, Principles of corporate Finance (ZAO "Olympus-Business", Moscow, 2010)

17. T. Copeland, Ph. Keenan, The McKinsey Quarterly, 2, 38-49 (1998)

18. A guide to body of knowledge project management (PMBOK guide) (2010)

19. L.A. Baev, Framework for the analysis of investment projects (Chelyabinsk, 2007)

20. G. Birman, S. Shmidt, Investments. Economic analysis of investment projects (YuNITI-Dana, Moscow, 2003)

21. T. Saati, The decision-making. Method of analysis of hierarchies (Radio and communication, Moscow, 1993)

22. E.V. Shikin, A.G. Chkhartishvili, Mathematical methods and models in management (Delo, Moscow, 2002) 